\title{
EROSION AND BREACHING OF COASTAL BARRIERS IN A CHANGING CLIMATE: ASSOCIATED PROCESSES AND IMPLICATION FOR CONTAMINATION OF COASTAL AQUIFERS
}

\author{
Saber M. Elsayed ${ }^{1}$, Hocine Oumeraci ${ }^{1}$ and Nils Goseberg ${ }^{1}$
}

\begin{abstract}
Europe and many other countries all over the world are often surrounded by coastal defence systems (e.g. protective dunes and dykes) in order to protect coastal areas from threats of wave attack, storm surges and subsequent coastal floods. During moderate sea conditions, wave attack and coastal erosion is limited to nearshore areas and may only cause shore erosion. Under the same conditions, fresh groundwater, which is hydraulically interconnected with seawater, is in equilibrium with the laterally intruding seawaters. Such equilibrium prevails as long as the moderate sea level (MSL) and the hydrogeological conditions at the sea/land boundary are stationary. However, during extreme storm surges, the higher water levels may temporally threaten the coastal defence systems. In fact, shortwaves riding on the temporally rising sea level during storm surge events may directly runup, rundown and/or impact on barriers, possibly causing seaward erosion followed by lowering of barrier's crest and hence wave overtopping or overflow through combined surge and waves. As a result, barriers may breach, inducing coastal inundation and subsequent vertical saltwater intrusion (VSWI) behind the breached barriers due to the vertical infiltration of inundating seawater into the fresh groundwater. In this study, a new integral physically based methodology is developed to reliably assess the possible implications of extreme storm surges on the safety of coastal barriers and the implications of possible breaching for contamination of coastal aquifers. The integral model is therefore capable to successively simulate breaching/overtopping of coastal barriers forced by storm surges as a hydraulic load, induced flood propagation in the hinterland and subsequent VSWI into coastal aquifers while considering the complexity of these processes and mutual interaction among them. The modelling methodology consists of an improved XBeach code (Roelvink et al., 2009) for hydro-morphodynamics unidirectionally coupled with the SEAWAT code (Langevin et al., 2008) for groundwater flow. The model is applied to a case study in northern Germany, showing that marine floods represent a serious threat to usability of coastal aquifers which are extremely important water resources. Outcomes of model application showed that a coastal flood event of a few hours may contaminate coastal aquifers for many decades, thus reducing the agricultural yield and hindering the sustainable development in coastal areas prone to coastal floods. This study represents, to the knowledge of the author, the first systematic research study that addresses the safety of natural coastal sandy barriers under extreme storm surge conditions together with the consequences of possible barrier breaching and overwash on subsequent flooding and saltwater intrusion into fresh groundwater. Moreover, it is probably the foremost study that attempts to mitigate storm-driven saltwater intrusion through the use and modelling of a subsurface drainage network. Besides improving the agricultural yield in coastal areas, the use of subsurface drainage network significantly reduces the natural remediation interval required for aquifers recovery after a coastal flood event. Moreover, it limits the vertical extent of the salt intrusion. The multiple flow domains and aspects discussed in this research make it a multidisciplinary study that is quite relevant for the coastal engineering community, for flood risk managers, for coastal hydrologists, for groundwater suppliers as well as for sustainable development planners.
\end{abstract}

Keywords: Coastal erosion; Breaching of coastal barriers; Wave nonlinearity; Soil-stabilization; Coastal inundation; Storm-driven saltwater intrusion; Contamination of coastal aquifers; Mitigation measure; Subsurface drainage.

\section{INTRODUCTION}

Natural disasters (e.g. extreme storm surges) and consequences of climate change on coastal areas represent serious threats to safety of coastal defence systems as well as to coastal groundwater resources. In fact, coastal areas and coastal aquifers are highly vulnerable and may experience severe impacts from coastal storms. Moreover, global warming and climate change might lead to changes in the frequency, intensity, spatial extent, duration and timing of weather events, possibly resulting in unprecedented extreme storm surges (Vousdoukas et al., 2016). Therefore, many coastal systems may experience accelerated coastal erosion, coastal barrier breaching and coastal flooding. Natural coastal barriers (e.g. protective dunes) as indicated in Fig (1.a) represent an important component of the defence system against storm surges, subsequent coastal floods and induced catastrophic consequences to human, lifelines, coastal ecosystems and landscapes. However, during an extreme storm surge event, water levels may temporarily increase from moderate sea level (MSL) as schematically shown in Fig (1.a) under the effect of speed wind and low pressure to higher surge level as shown in Fig (1.b). As a result, barriers become directly attacked by shortwaves riding on the surge leading to wave impact, wave run-up, overtopping and possibly to inundation when the maximum runup level exceeds the minimum crest level. Subsequently, barriers may be breached, inducing coastal inundation and subsequent vertical seawater intrusion (VSWI) into fresh coastal groundwaters (Elsayed and Oumeraci, 2018).

\footnotetext{
${ }^{1}$ Division of Hydromechanics and Coastal Engineering, Leichtweiß Institute for Hydraulic Engineering and Water Resources, Technische Universität Braunschweig, Beethovenstraße 51a, 38106 Braunschweig, Germany. Email: $\underline{\mathrm{s}}-$ m.elsayed@tu-braunschweig.de
} 


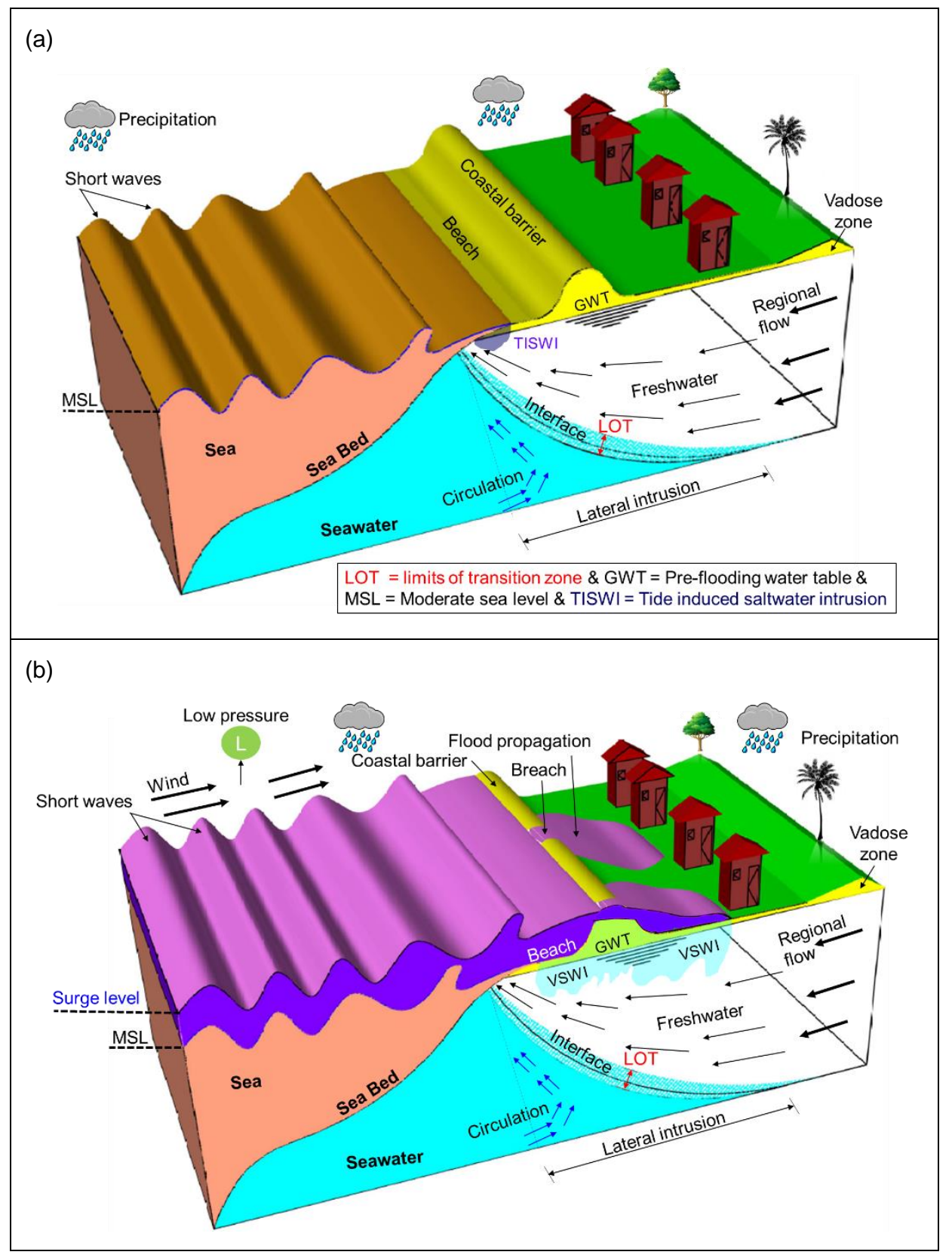

Fig. 1: Sea/land boundary: (a) during moderate sea conditions where coastal erosion is limited to the active zone near beach and where the intrusion is lateral besides the tide-induced intrusion (TISWI), and (b) during an extreme storm surge event where sea water level increases, possibly resulting in barrier breaching, coastal inundation and subsequent vertical saltwater intrusion (VSWI) into aquifers. The precipitation and the regional flow induced by differences in hydraulic gradients support long-term natural remediation of aquifers.

Though coastal aquifers represent an important source of fresh water for drinking, domestic, irrigation or industrial purposes in coastal areas and in atoll islands may represent the only source of freshwater, they are extremely sensitive to saltwater intrusion, particularly the vertical intrusion induced by coastal floods (Elsayed and Oumeraci, 2017a). Moreover, contaminations of freshwater aquifers as a result of VSWI may last for decades until aquifers are restored naturally (Elsayed and Oumeraci, 2018, 2017b). In fact, submarine groundwater discharge (i.e. the regional flow) induced by difference in hydraulic gradients as shown in Fig (1) supports such a long-term aquifers remediation. Nevertheless, sustainable development of highly-populated coastal areas and the need for water supply from coastal aquifers due to increased demographic movements to coastal areas and increased irrigational demands for the agricultural sector might also be affected owing to the long-lasting remediation of contaminated 
groundwater resources and thus to the need for more treatment costs to cover such demands. Therefore, there is an urgent need to an integral modelling/prediction tool that can successively and reliably (i) simulate the breaching/overtopping of earthen coastal barriers, (ii) predict the inland discharge and its propagation in the hinterland and (iii) accurately estimate the long-term remediation of coastal aquifers after a flood-induced VSWI. In fact, reliable prediction of storm-induced coastal erosion and breaching is crucial to reliably predict the induced inland discharge and subsequent flood propagation. Moreover, it is necessary to accurately consider the significant sensitivity of coastal aquifers to VSWI and to reliably predict the extent and remediation times of aquifers after a VSWI event. As a result, effect of VSWI as an environmental risk on sustainable development of coastal areas might be adequately assessed and included in future flood risk assessments. Moreover, appropriate mitigation measures might be suggested to mitigate the VSWI and to shorten the natural remediation time of coastal aquifers as a risk receptor.

The modelling of a breaching-induced VSWI event represents a very challenging task due to the high diversity and complexity of the processes/interactions to be considered. Different flow domains are involved starting from the sea where waves propagate toward the coastal barriers (Fig 1), which might result in excessive wave overtopping and/or barrier breaching, thus leading to coastal floods behind the barriers and subsequently to VSWI. On the other hand, diverse processes are involved (e.g. coastal hydrodynamics, sediment transport, soil avalanching on barriers' slopes and/or from breaching wedges, surface runoff of seawater over the hinterland and subsurface flow of the infiltrating seawater). In addition, several interactions among the latter processes exist. For instance, the breaching process represents the outcome of complex interactions between hydrodynamics, sediment transport and soil avalanching processes (Elsayed and Oumeraci, 2016a). Furthermore, propagation of salt water over the hinterland and subsequent infiltration to aquifers represent a surface-subsurface interacting transport of a conservative solute (Elsayed and Oumeraci, 2017b).

Though breaching, subsequent flooding and saltwater intrusion are naturally successive and hydraulically interconnected processes, the complexity of these three main processes has led to split the modelling by considering each individual process separately. As a result, no integral model yet exists to reliably assess the vulnerability of coastal defences to breaching under extreme storm surges and to draw the implications of breaching-induced coastal floods for the contamination of coastal aquifers. Moreover, the decoupled modelling approach does not account for the interactions among these processes, thus requiring a "manual" transfer of the results of one model as input boundary conditions to another model (Elsayed and Oumeraci, 2018, 2017a). Therefore, the main objectives of this study are (i) to provide an improved understanding of breaching of coastal barriers, induced inundation and subsequent VSWI, (ii) to address the modelling of these processes in an integral and well-validated modelling approach by considering the multidirectional interactions among these processes, (iii) to draw implications of coastal floods for groundwater contamination, and (iv) to examine the suitability and performance of a subsurface drainage network as a structural mitigation measure to mitigate the VSWI during and after coastal floods. To achieve these objectives, a new modelling approach (Elsayed, 2017) is developed to successively simulate these processes. The proposed modelling approach utilises an improved version of the open-source and freely available code XBeach (Roelvink et al., 2009) for simulating overtopping/breaching of dunes and other natural coastal barriers and subsequent flooding and SEAWAT (Langevin et al., 2008) for simulating the VSWI. The components of the model system are systematically validated with large-scale GWK tests for dune erosion and further diverse data from the literature, and the entire model system is applied to a case study near Bremerhaven in northern Germany. Section 2 describes the rationale behind this model system. Section 3 presents the outcomes of the validation of the XBeach model using large-scale GWK tests as well as the formulation and implementation in XBeach of two new physical processes to enhance the capability of XBeach for the prediction of coastal barrier breaching. Section 4 presents the outcomes of the combined modelling of breaches and induced induction using XBeach. Section 5 presents the implications of coastal floods for groundwater contamination using the outcomes of applying the model system to a case study near Bremerhaven. Section 6 summarizes the effect of using subsurface drainage as a mitigation measure to improve the resilience of coastal aquifers against marine floods. Section 7 presents a summary of the results, their limitations and the implications for coastal engineering practice including future flood risk assessments and sustainable development in coastal areas.

\section{THE XBEACH-SEAWAT MODEL SYSTEM}

A storm surge is a rapid short-term rise of the sea level as a very long wave which may last several hours or even days. As a result, wind-induced shortwaves riding on storm-tide level may result in barrier erosion and breaching (Fig 1). Breaching of coastal barriers represents one of the most important sources 
of coastal flooding, where breach induced inlets work as pathways to inland inundation and subsequent VSWI. Breaching is a complex hydro-geo-morphodynamic process, which is commonly initiated when water overflows a depressed portion in a narrow landmass such as a barrier spit, a barrier island or a protective dune. Given sufficient duration and intensity, the flow will induce a breach (channel/inlet) that causes water to flow across the breached barrier. Nevertheless, the initiation of a coastal barrier breach is more complex than this common case, as it depends on the relationship between the storm-tide level and the crest level of the barrier, which is not necessarily beneath the extreme water level (Elsayed and Oumeraci, 2016a). During relatively fast events (e.g. storm surges), the processes that may initiate a barrier breach, as shown in Fig (2), are: (i) Impact/collision of breaking waves, (ii) Wave run-up and rundown, (iii) wave overtopping/overwash, (iv) Overflow of combined waves and surge and (v) seepage and piping. The first two processes may initiate a breach from the seaward (Stanczak, 2008) while the rest may initiate a breach from the landward (D'Eliso, 2007). As a result, a breach may develop and widen due to the hydrodynamic interaction with sediments and the induced sediment transport from the breach bed and wedges and the subsequent soil avalanching from barrier sides and breach wedges due to the hydro-morphodynamic-induced local slope instabilities. Therefore, rather than starting with developing a new breaching model that can simulate these diverse processes for breach initiation and growth, selection of a state-of-the-art breaching model that can simulate these processes in a processesbased manner is favoured.

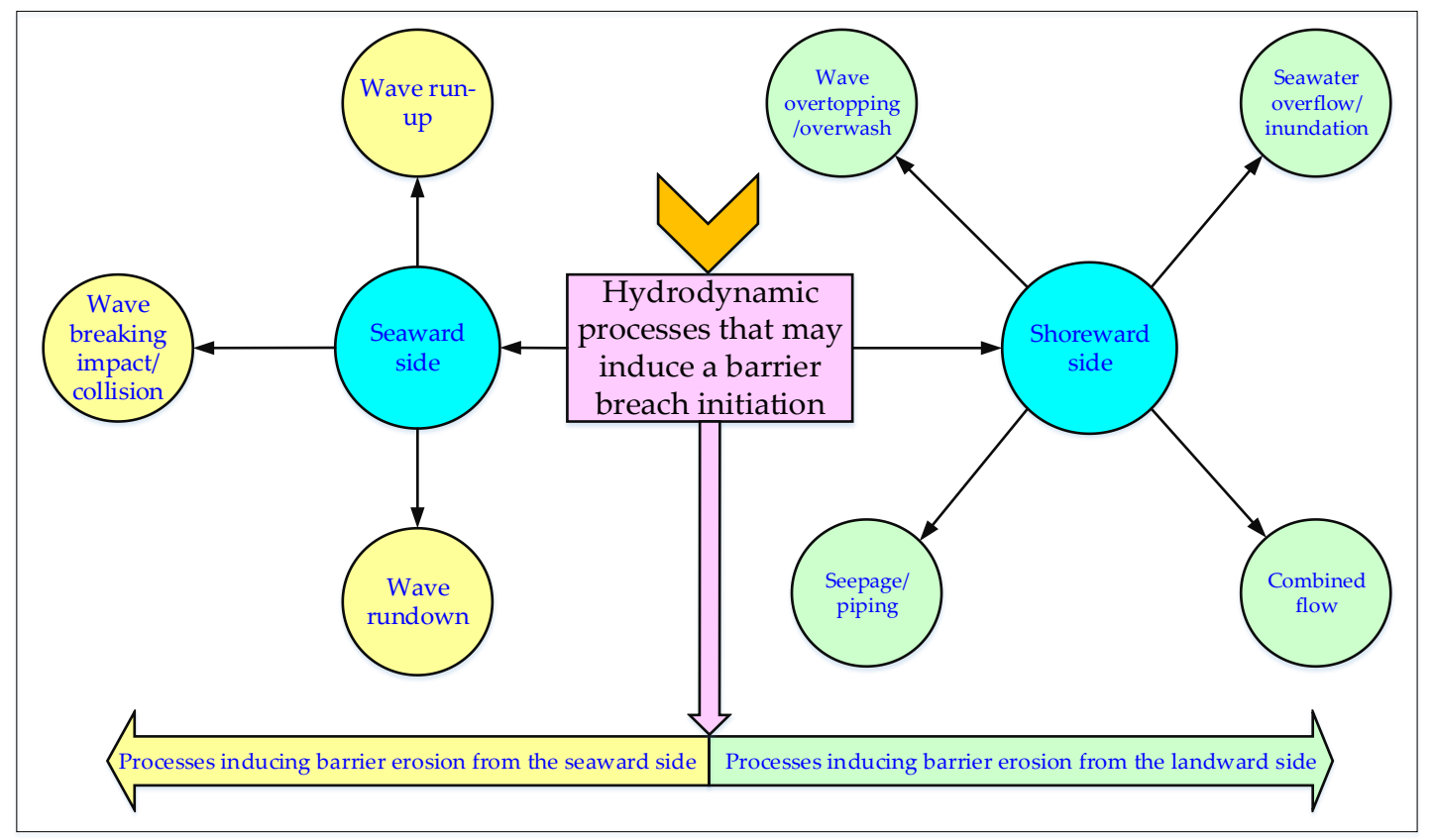

Fig. 2: Hydrodynamic processes that may initiate a coastal barrier breach from seaward and landward sides, depending on the relationship between the storm-tide level and crest level of the barrier.

XBeach is selected as the most appropriate model to simulate the aforementioned hydro-geomorphodynamic processes. Moreover, in its two-dimensional horizontal (2DH) form, XBeach is capable of describing local discontinuities or depressions in barrier crest by imposing the longshore and crossshore variations of topography/bathymetry. Furthermore, XBeach has sufficiently proved his capability to predict overtopping rates as compared to empirical equations and/or neural network tool recommended by static models (e.g. EurOtop of Van der Meer et al. 2016), which are also unsuitable to calculate the inland discharge through a breach-induced inlet because of the dynamic nature of the breaching process (Elsayed and Oumeraci, 2017c). In addition, XBeach is capable to generate long and short-crested waves at the offshore boundary (Elsayed and Oumeraci, 2016a, 2016b). The latter wave type represents a real sea state and is often described by a JONSWAP (Joint North Sea Wave Project) spectrum at the off-shore boundary, thus representing an alongshore shore varying hydraulic load due to the longshore variability of the wave height. XBeach, in addition, describes the propagation of long waves and currents deterministically using the Generalised Lagrangian Mean (GLM) form of the non-linear shallow water equations (NLSWEs). The latter are generally solved in common flood propagation models using an Eulerian representation (e.g. River-2D, TELEMAC-2D and TUFLOW). As demonstrated in Elsayed and 
Oumeraci (2016a), XBeach is capable to simulate the breaching process and induced inundation in a single simulation and using a single mesh for the coastal zone and the adjacent hinterland without the need to transfer of boundary conditions between a breaching model decoupled with an inundation model. In this way, mutual interactions between the breaching and induced inundation are also considered. Thus, XBeach represents currently the most appropriate model to calculate breaching dimensions and inland discharges required to reliably predict VSWI extent and natural remediation interval. Nevertheless, due to its simple groundwater module based on Darcy equation, XBeach cannot account for subsurface mass transport (e.g. for SWI). Therefore, the XBeach code, as a surface model for both breaching and flood propagation, is unidirectionally coupled with the SEAWAT code (Langevin et al., 2008) as a subsurface model, which is capable to simulate fully coupled groundwater flow (also using 3D Darcy equation) and solute transport (using the advection-dispersion equation). Thus, the XBeach-SEAWAT model system proposed and tested in this study represents an integral surface-subsurface model system capable of (i) simulating coastal erosion and breaching as well as the induced inundation and (ii) considering the implications of breaching/overtopping-induced coastal floods for groundwater contamination and subsequent natural remediation. SEAWAT is selected among other solute transport models (e.g. SUTRA, OpenGeoSys) because it includes a ready to use drainage package that can be adapted to simulate the subsurface drainage effect on VSWI as a structural measure suggested to mitigate the VSWI and to shorten the long time needed for aquifers natural remediation as elaborated in the following sections.

\section{EROSION AND BREACHING OF COASTAL BARRIERS: LIMITATIONS OF XBEACH AND PROPOSED NOVEL PHYSICAL PROCESSES FOR IMPLEMENTATION}

\section{Assessment of XBeach Performance by Means of Large-Scale Dune Erosion Data}

As aforementioned, reliable prediction of coastal erosion and breaching of coastal barriers is crucial to achieve reliable estimations of inland discharges, flood depths and intrusion extent and subsequent dilution time. Therefore, the performance of the XBeach model is examined using a unique dataset from 17 large-scale model tests for dune erosion (hereafter called GWK-tests), which were performed in 2013 by Leichtweiß-Institut (LWI) in the Großer Wellenkanal (GWK) of the Forschungszentrum Küste (FZK) to physically simulate the erosion from the seaward side of the sand dunes in the western zone of the Wangerooge Island, northern Germany. The GWK-tests were performed using the results of site investigations for the wave conditions and their dominant directions, which are briefly summarised in Elsayed and Oumeraci (2015a). The large-scale experiments were performed on five cross-shore profiles in GWK subject to the same wave conditions (significant wave height of $1.1 \mathrm{~m}$ and peak period of $6.6 \mathrm{~s}$ ) and different still water levels so that a wide range of wave overtopping rates could be achieved. For all profiles, the dune extension with a front slope 1:1 is built behind the crest of a revetment similar to that in Wangarooge with different dune offset from the revetment crest as shown in Fig (3).

\begin{tabular}{|l|l|l|}
\hline (a) Dune extension without offset & $\begin{array}{l}\text { (b) Dune extension with } 3.33 \mathrm{~m} \text { wide } \\
\text { offset }\end{array}$ & $\begin{array}{l}\text { (c)Dune extension with 6.66 } \mathrm{m} \text { wide } \\
\text { offset }\end{array}$ \\
\hline $\begin{array}{c}\text { Revetments crest } \\
\text { Revetments }\end{array}$ & Revetments
\end{tabular}

Fig. 3: Physical model setup in GWK: dune extension with a front slope of 1:1 is built behind the revetment crest with (a) no offset for profiles 1 and 3 , (b) with offset of $3.33 \mathrm{~m}$ width for profiles 2 and 4 , and (c) with double offset of $6.66 \mathrm{~m}$ width for profile 5 .

Using the non-modified XBeach (revision 4812), GWK-tests are numerically reproduced for the same laboratory conditions. Part of the outcomes is shown in Fig (4). The results, in general, showed a relatively reasonable prediction capability for the scour behind the revetment and the frontal dune erosion, illustrating that XBeach is generally suitable for simulating coastal erosion. However, the results also revealed that the prediction performance got worse for higher overtopping rates (e.g. Fig 4.b for wave overtopping rate of $423 \mathrm{l} / \mathrm{s} / \mathrm{m}$ ) than for lower wave overtopping rates (e.g. Fig 4.a for overtopping rate of $16.35 \mathrm{l} / \mathrm{s} / \mathrm{m})$. This means that the prediction capability of XBeach might substantially decrease with higher overtopping rates, which is in full agreement with the overestimation of erosion associated 
with higher flow velocity regimes as often reported in the literature (e.g. Bisschop et al., 2016, 2010; De Vet, 2014; Elsayed and Oumeraci, 2017c; McCall et al., 2010). As shown in Fig (4.c), this overestimation by XBeach is verified by comparing the observed and the modelled crest recession for all the 17 GWKtests.

Both crest recession (Fig 4.c) and scour size behind the revetment crest (e.g. Fig 4.a and 4.b) are overestimated by about $70 \%$ in average. However, the mismatch between the observed and calculated profiles vanishes with lower overtopping rates (e.g. tests 01-03) and also with increasing distance of the dune offset from the revetment crest (e.g. test 08). Overcoming/reducing such an overestimation represent the primary motivation for implementing and testing further physically-based improvements in the XBeach model (see Section 3.2), before using it for barrier breaching. As a result, an improved breaching model is obtained to calculate with a more adequate accuracy the inland discharge through breaching-induced inlets and hence the flood propagation in the hinterland and subsurface flow of the seawater percolating into the groundwater.



Fig. 4: Measured and predicted (by XBeach) cross-shore profiles: (a) with a lower wave overtopping rate of $16.35 \mathrm{l} /(\mathrm{s} \cdot \mathrm{m})$, (b) with a higher wave overtopping rate of $423 \mathrm{l} /(\mathrm{s} \cdot \mathrm{m})$, and (c) modelled vs observed crest recessions for the GWK-tests 01-17 with different wave overtopping rates (1.92-423 I/(s.m)) and with different widths of dune offsets $(0-6.66 \mathrm{~m})$.

\section{Improvement of Modelling of Sediment Stirring in XBeach}

Rather than using artificial (non-physically based) limiters to overcome the erosion overestimation, which is common with XBeach for high flow velocity regimes (e.g. McCall et al., 2010; Muller et al., 2016), and in order to improve the prediction capability of XBeach in terms of erosion and overwash volumes, two physical processes responsible for these overestimations are identified: (i) the wave nonlinearity effect on sediment transport, which is currently described in XBeach by a calibration factor 
for the time-averaged flow depending on the wave skewness and asymmetry and (ii) the considerable excess of the shear stress actually required to initiate the sediment particle motion as compared to that predicted by the common Shields' criterion for incipient motion. The importance of examining these two processes arises from the fact that they are the governing processes of sediment stirring in XBeach. Thus, two new improvements, related to these two processes which are responsible for the aforementioned overestimation, are introduced and implemented in the model (Elsayed and Oumeraci, 2017c, 2015b). The improved XBeach model is then tested for dune erosion, for barrier breaching as well as for a barrier island erosion and overwash under an extreme storm surge event. The results showed a very good prediction capability of the improved model. Meanwhile, since their publication in (Elsayed and Oumeraci, 2017c), these model improvements have been applied in several research studies (e.g. Park et al., 2018) to improve the prediction capability of XBeach. The rationales behind these two model improvements are elaborated below.

\section{(a) Bed slope effect on wave nonlinearity and sediment transport}

The surfbeat mode of XBeach, which is commonly used in practical morphology studies, does not directly simulate the wave shape. Thus, intra-wave processes (e.g. skewness and asymmetry) are not explicitly computed. The increase in skewness and asymmetry has important implications for the waveinduced net cross-shore sediment transport as it results in an increase of onshore sediment transport and therefore may be one the reasons behind overestimation of sediment erosion. In order to indirectly account for these changes of the wave shape within XBeach, a skewness and asymmetry discretization model is used that takes the following form

$$
u_{a}=\gamma_{u a} u_{r m s}\left(S_{k}-A_{s}\right)
$$

Where $u_{a}$ is a net flow velocity that transports sediment onshore under the effect of nonlinear waves; the values of wave skewness $S_{k}$ and wave asymmetry $A_{s}$ are parameterized as a function of the Ursell number; $u_{r m s}$ is the root-mean-squared orbital velocity. The parameter $\gamma_{u a}$ is defined in XBeach by the keyword facua (factor for $u_{a}$ ) and has a default value of 0.1 . It represents in fact one of the most important parameters in XBeach as it is the only parameter mostly affecting the net cross-shore sediment transport. In this study and based on date collected from the literature as shown in Fig (5.a), it is shown that this parameter depends on beach slope steepness $S_{S}$ (measured perpendicularly to shoreline from the closure depth to the foredune (rise over run)). As a result, Eq (1) is modified in the XBeach code to the form in $\mathrm{Eq}(2)$

$$
u_{a}=5.93 s_{s}^{1.35} u_{r m s}\left(S_{k}-A_{s}\right)
$$

Eq (2) provides a proper value for $u_{a}$, which affects both the sediment entrainment/deposition and total sediment transport rates and thus may contribute to solve the overestimation problem through stirring more sediment onshore. Therefore, this model improvement proves that onshore sediment transport depends on beach slope.

\section{(b) Grain-stabilization effect on the inception of sediment motion}

The classical Shields criterion for the inception of sediment motion does not account for the graininterlocking effect and the soil texture effect, which are more pronounced for natural mixed-grain-size sediment beds than for uniform sediment beds. Therefore, a large part of the erosion overestimation by XBeach is assumed to be attributed to the underestimation of the critical Shields parameter for incipient sediment motion. Elsayed and Oumeraci $(2017 \mathrm{c})$ have demonstrated that there are unaccounted forces in the formulation of the critical Shields parameter such as (i) the uprooting force to overcome the sediment interlocking, especially for consolidated/compacted soils and (ii) biological and/or chemical (salty) stabilizations. Thus, the overestimation of the erosion rates by XBeach can partially be attributed to the omission of such grain-stabilizing effects on critical bed shear stresses for incipient sediment motion. The additional shear stress required to account for these effects are implemented in XBeach by amplifying the critical Shields parameter (as schematically shown in Fig 5.b) and hence the critical stirring velocity $U_{c r}$, using an amplification factor $\gamma_{p i}$ as follows

$$
U_{c r}^{2}=\frac{\theta_{c}(s-1) g D_{50}}{c_{f}} \rightarrow U_{c r_{p i}}^{2}=\frac{\theta_{c_{p i}}(s-1) g D_{50}}{c_{f}} \rightarrow U_{c r_{p i}}=\gamma_{p i} U_{c r} \rightarrow \theta_{c_{p i}}=\gamma_{p i}^{2} \theta_{c}
$$

Where $C_{f}$ can be calculated based on the roughness coefficient of Chezy $c_{c h}$ or Manning $n$ and $g$ is the gravitational acceleration. The critical stirring velocity $U_{\mathrm{cr}}$ is mainly a function of the sediment properties (e.g. mean diameter $D_{50}$ and specific gravity s) and of the critical Shields parameter $\theta_{c} \cdot \gamma_{p i}$ is a new calibration factor for the grain-stabilization and Particle Interaction effect (called "facpi") that 
considers the increase of the shear stresses required to initiate the sediment motion by amplifying $U_{c r}$ to $U_{c r_{p i}}$ and thus reduces sediment stirring because of decreasing the mismatch between actual mobilizing flow velocity and critical velocity for initiation of sediment motion. Though this model modification represents a relatively small contribution, it was capable to explain, for the first time, the role of bed soil stabilization status in sediment stirring and transport and to substitute the use of artificial sediment transport limiters which cannot be physically explained. In fact, soil resistance (grain-stabilization effect) represents one of the main factors governing coastal erosion, coastal morphology and breach development. Thus, this contribution justifies why some soils undergo more erosion than others based on their grain stabilization status. Higher values for facpi indicate indeed higher soil resistance to erosion due to grain-stabilization. Moreover, this model modification opens the way toward further research (i) to establish physically-based predictors for the calibration factor facpi $\left(\gamma_{p i}\right)$ based on soil properties (e.g. median grain size and void ratio as a measure of the compaction degree of sandy soils), and (ii) to account for spatially varying soil resistance to erosion, which is crucial for reliable prediction of possible locations of barrier breaching initiation.

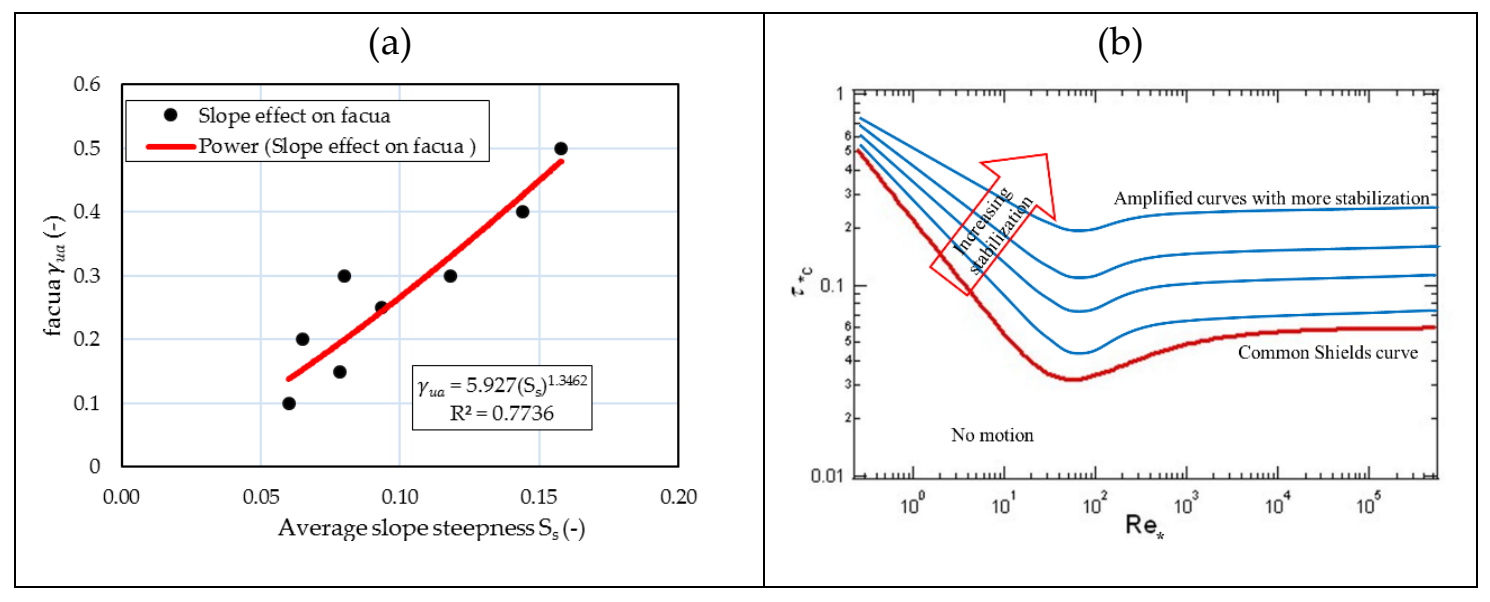

Fig. 5: Proposed novel improvements of XBeach: (a) Relation between the average seaward slope steepness and facua parameter that is responsible for sediment stirring under nonlinear waves and (b) amplified critical shields parameter to account for the effect of diverse forms of grain-stabilization.

\section{(c) Validation of model modifications}

The performance of the improved XBeach model was examined for three selected test cases (see Elsayed and Oumeraci, 2017c). The selection of these cases was mainly based on the need to separately test the effect of the proposed improvements on (i) frontal dune erosion (the large-scale GWK-tests mentioned above are used for this purpose), (ii) sand barrier breaching and (iii) erosion and overwash of a barrier island under an extreme storm surge. It is noticed that for all test cases, the default XBeach settings result in significant overestimates of the erosion rates. However, this overestimation is overcome using the proposed improvements, which means that the improved XBeach model now represents a more adequate tool to predict erosion rates, breaching dimensions and inland discharges to the hinterland.

\section{COMBINED MODELLING OF COASTAL BARRIER BREACHING AND INUNDATION USING THE IMPROVED XBEACH CODE}

Coastal floods induced by breaching/overtopping of coastal barriers represent a multi-scale problem governed by complex interactions between a variety of hydrodynamic and sediment-related processes at multiple time and spatial scales. However, the state-of-the-art modelling of a barrier breaching and the induced inundation is often based on decoupled modelling of these two processes, based on transferring the inland discharge from a breaching/overtopping model to another flood propagation model, thus ignoring the strong interaction between them. Moreover, such traditional modelling approach considers only the mass conservation by transferring from the breaching model to the inundation model the inland discharge that is commonly known as inland hydrograph $\mathrm{Q}(\mathrm{t})$. Such decoupled approaches often omit the momentum transfer between both models, leading to incorrect computations of the flood propagation in the hinterland. For this reason, and in order to consider the successive processes, this study demonstrated that the XBeach model can be applied to simulate in combination, the breaching process and the induced flood propagation in a single model. This means that XBeach is not only an erosion and 
breaching model, but it successfully serves also as a flood propagation model, so that two-way interactions and transfer of both mass and momentum are considered between breaching and flood propagation (see Elsayed and Oumeraci (2016a, 2016b) for more details).

For instance, Fig (6) shows a one-dimensional example for both decoupled (using XBeach as a breaching/overwash model and the famous HEC-RAS model by US Army corps of Engineers as a flood propagation model) and XBeach alone for combined modelling of breaching/overwash and induced inundation.

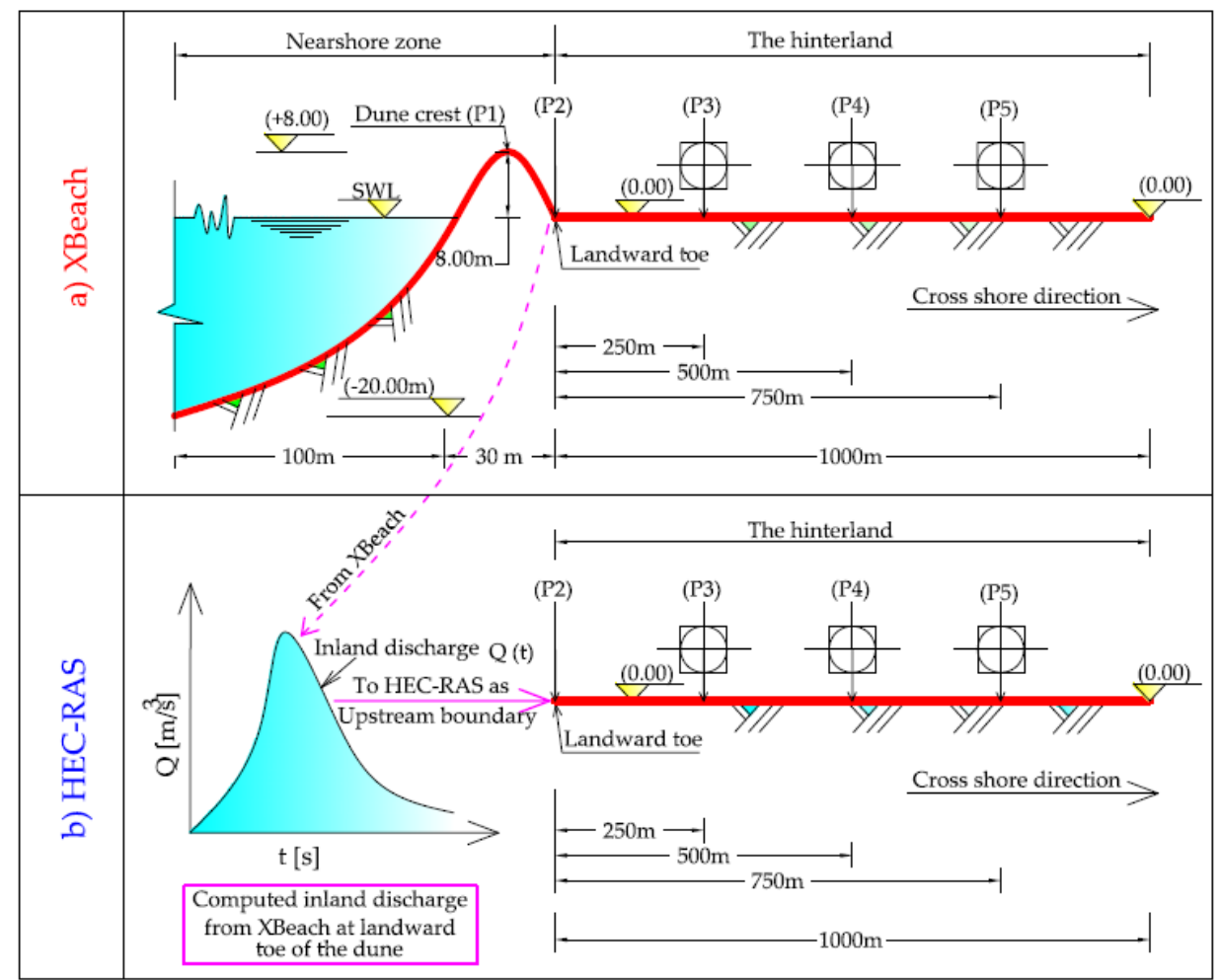

Fig. 6: 1D synthetic cross-shore profile used in XBeach (a) to simulate a 1D overwash event and the induced flood propagation in the hinterland and $(b)$ the inland discharge $Q(t)$ is computed from XBeach at point $P 2$, where $Q(t)$ serves as inflow boundary condition for the HEC-RAS inundation model for the hinterland. The outcomes of the inundation from XBeach and HEC-RAS are compared at the reference points P3, P4 and P5.

Coastal erosion and overwash are forced for the synthetic cross-shore profile in Fig (6) for one hour by synthetic surge and wave conditions. For the decoupled approach, the inland hydrograph is computed at the landward toe of the barrier (i.e. at point P2) and transferred to HEC-RAS as an upstream boundary condition. For the combined modelling by XBeach, the boundaries are "automatically" transferred between both processes. In Fig (7), the water profiles at different times are plotted and water depths and velocities at the points (P3-P5) are computed, showing that the decoupled modelling provides meaningless water levels (water level in the hinterland exceeded the seawater level), especially at times $45 \mathrm{~min}$ and $60 \mathrm{~min}$ due to the omission of the momentum transfer in the decoupled approach. In fact, flow velocity $\mathrm{u}(\mathrm{t})$, which is also crucial as it provides together with $\mathrm{Q}(\mathrm{t})$ the momentum, cannot be accounted for in the inflow conditions of the flood propagation model in decoupled approaches. Moreover, the decoupled approach cannot account for the evolution of the inflow width at the upstream boundary in the common inundation models, which also affect the flood kinematics in the hinterland. Such evolution of inflow width arises from the dynamic nature of the breaching process, i.e. the breach growth (widening and deepening of the breaching dimensions) with time.

The omission of the momentum transfer in the decoupled modelling approach leads to higher calculated water depths. Therefore, computed water depths by the decoupled approach were higher at Points (P3-P5) as shown in Fig (7.b). As a result, the computed flow velocities using the decoupled approach were lower at the same measuring points as shown in Fig (7.c). This generally means that decoupled approaches provide incorrect flood extents, water depths and flow kinematics. For this reason, the use of XBeach as a model for combined modelling of overtopping/breaching and induced inundation is suggested. 
(a)

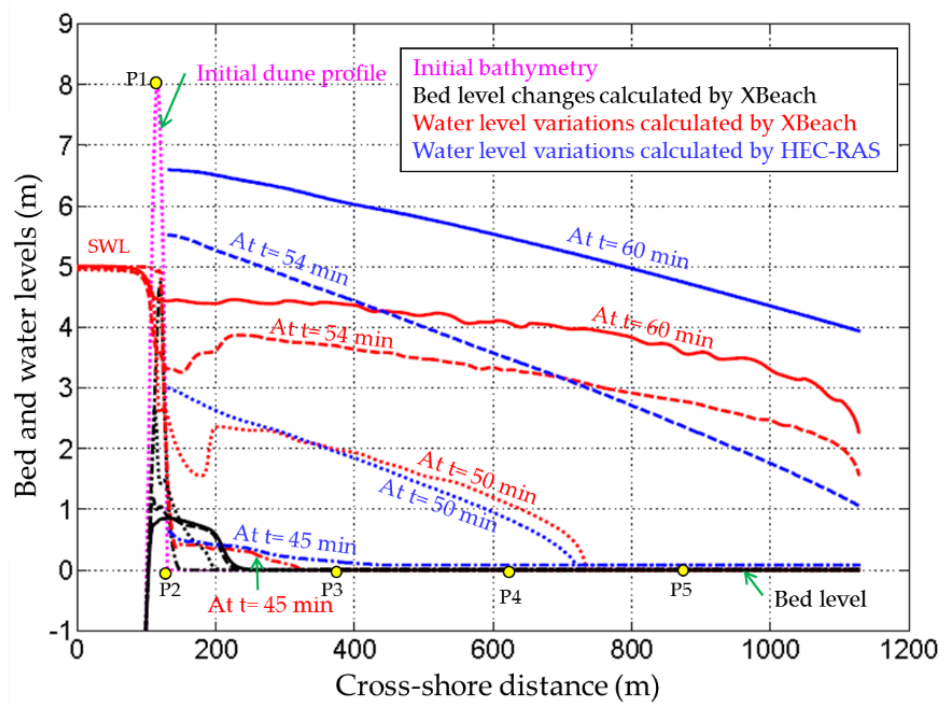

(b)



(c)

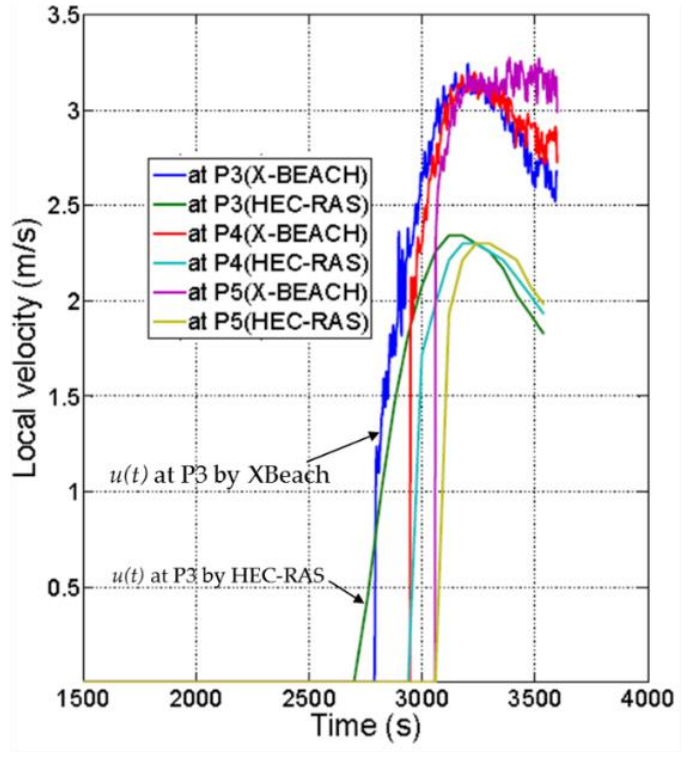

Fig. 7: Comparison of outcomes using decoupled overwash and inundation and combined modelling by XBeach: (a) water levels calculated at times 40, 50, 54 and 60 mins, (b) water depths and (c) local depthaveraged velocities calculated at the measuring points P3, P4 and P5.

In order to demonstrate that the XBeach model can be applied as a flood propagation model, besides being a model for nearshore hydro-morphodynamic processes, the mathematical formulation of XBeach is compared to the mathematical formulation of common flood propagation and inundation model (e.g. River-2D by University of Alberta and BASEMENT by ETH Zürich), showing that both models are based on the nonlinear shallow water equations NLSWEs. However, XBeach utilizes the Generalised Lagrangian Mean (GLM) approach which applies a more generic representation of the bed shear stresses and the depth-averaged velocities rather than the Eulerian representation that is commonly used in the common flood propagation model. The GLM approach unambiguously splits a motion into a mean part (Eulerian) and an oscillatory part (Lagrangian), providing a mixed Eulerian-Lagrangian description for the flow field for wavy water surfaces but appointed to fixed Eulerian coordinates. The GLM approach applies therefore to any problem, whose governing equations are given in Eulerian form (e.g. common inundation models), with a more thorough representation of the real processes. The latter means that 
XBeach can also function as a flood propagation model and may, therefore, be applied to simulate, in combination and successively, the breaching and induced inundation over a single mesh containing nearshore bathymetry and hinterland topography, with the capability of simulating the mutual interactions and the induced morphodynamics, including soil avalanching. As a result, the aforementioned drawbacks of the decoupled approach are overcome and reliable kinematics of flood propagation are obtained.

In order to validate the previously improved XBeach for combined breaching and induced inundation in a single model, it is applied to the Het Zwin breaching and inundation test (see Elsayed and Oumeraci (2016a) for further details). The outcomes well-illustrated that XBeach is capable to accurately calculate breach dimensions and to reasonably predict the flow kinematics and water depths in the hinterland. The main outcome of this phase of the analysis is that a well-validated improved XBeach model is now available not only to provide a reliable assessment of the safety of dunes and coastal sand barriers under future extreme storm conditions but also to reliably predict the flood propagation in coastal areas. Such a combined modelling approach can, therefore, be used in reliable assessments of flood risk to human, their assets, public lifelines and strategic infrastructures. Moreover, it can be used to assess the risk of groundwater contamination induced by seawater infiltrating behind breached coastal defences during and after coastal floods as discussed in the following section.

\section{IMPLICATIONS OF COASTAL FLOODS FOR GROUNDWATER CONTAMINATION}

During and after a coastal flood event, seawater infiltrates vertically behind overtopped/breached coastal defences as illustrated in Fig (1), inducing coastal aquifers contamination due to the VSWI. Such vertical infiltration of seawater has a substantial impact on the dynamics of coastal aquifers as well as on the salinity distribution in such aquifers. Even a moderate storm surge event may significantly affect the usability of coastal aquifers for decades (Elsayed and Oumeraci, 2018, 2017b). In Section 4, XBeach is successfully applied to integrally simulate the mutual interaction between storm-induced barrier breaching/overtopping and the subsequent surface propagation of the flooding water while omitting the subsurface flow (i.e. the infiltration process) and the accompanied salinity increase of the originally fresh aquifers. Because intrusion of seawater into aquifers is a complex hydrodynamic process associated with the motion of fresh and salt waters with different masses/densities, a subsurface module is necessary to simulate coupled groundwater flow as well as advection and dispersion of a solute (e.g. seawater) in porous media. Though XBeach, which simulate both breaching and subsequent inundation, has a groundwater flow module solving the 3D Darcy equation, it cannot yet simulate contaminant transport because it does not yet include the advection-dispersion equations. Consequently, this study suggested using the XBeach model to perform the combined modelling of breaching and inundation while the saltwater intrusion (SWI) is simulated separately using the SEAWAT module of Visual Modflow using the outcomes of XBeach (i.e. water depths and flood extent) as a surface boundary.

The case study near Bremerhaven makes use of available hydrogeological data and geophysical information for a 12-km long vertical cross-section belongs to the German Bight, which is situated north of Bremerhaven, northern Germany. Fig (8) shows the location of this cross-section on the map of Germany and the topography of this profile as well as the applied storm surge event, which induce dyke overtopping and flood propagation behind the dyke (the dyke is considered non-erodible through increasing the value of Manning coefficient $n_{2}$ in Fig 8.e over the dyke).

The considered storm surge (Fig. 8.d) induces a maximum SLR up to 8.5 m.a.s.1., which is about 1.1 $\mathrm{m}$ higher than the dyke crest without consideration of the effects induced by short-waves (e.g. wave runup). Thus, this storm surge event results in overtopping flow over the dyke crest for $2.8 \mathrm{~h}$. Subsequently, seawater inundates the hinterland behind the dyke, where the sea water infiltrates into the soil and percolates through the unsaturated (vadose) zone towards the groundwater table. Therefore, the storm surge event includes the following processes (i) sea level rise (SLR) due to surge, (ii) overtopping/overflow and ponding, (iii) sea level dropping and pond reduction, and (iv) recovery of aquifer salinity to the initial state (remediation) under effect of seaward directed flow and vertical recharge of precipitation. In fact, seaward directed flow and infiltrated precipitation generate an effective hydraulic barrier to impede further inland migration of saltwater and provide a downgradient freshwater discharge for saltwater dilution and flushing counteracting the effects of storm surge on the extent of vertical SWI.

Using the improved XBeach model as a combined overtopping and flood propagation model, two modelling scenarios for the free surface flow are considered: (i) Morpho-off scenario considers that no morphological evolution takes place because both the dyke and the beach area are highly protected against coastal erosion and overwash, and (ii) Morpho-on scenario considers that coastal erosion and 
associated morphological changes may occur over the whole study area when the flow velocity exceeds the threshold value for the onset of sediment motion as described by the Shields' criterion for incipient sediment motion. The rationale behind these scenarios is to understand the effect of unprotected coastal barriers on coastal flooding and subsequent SWI.

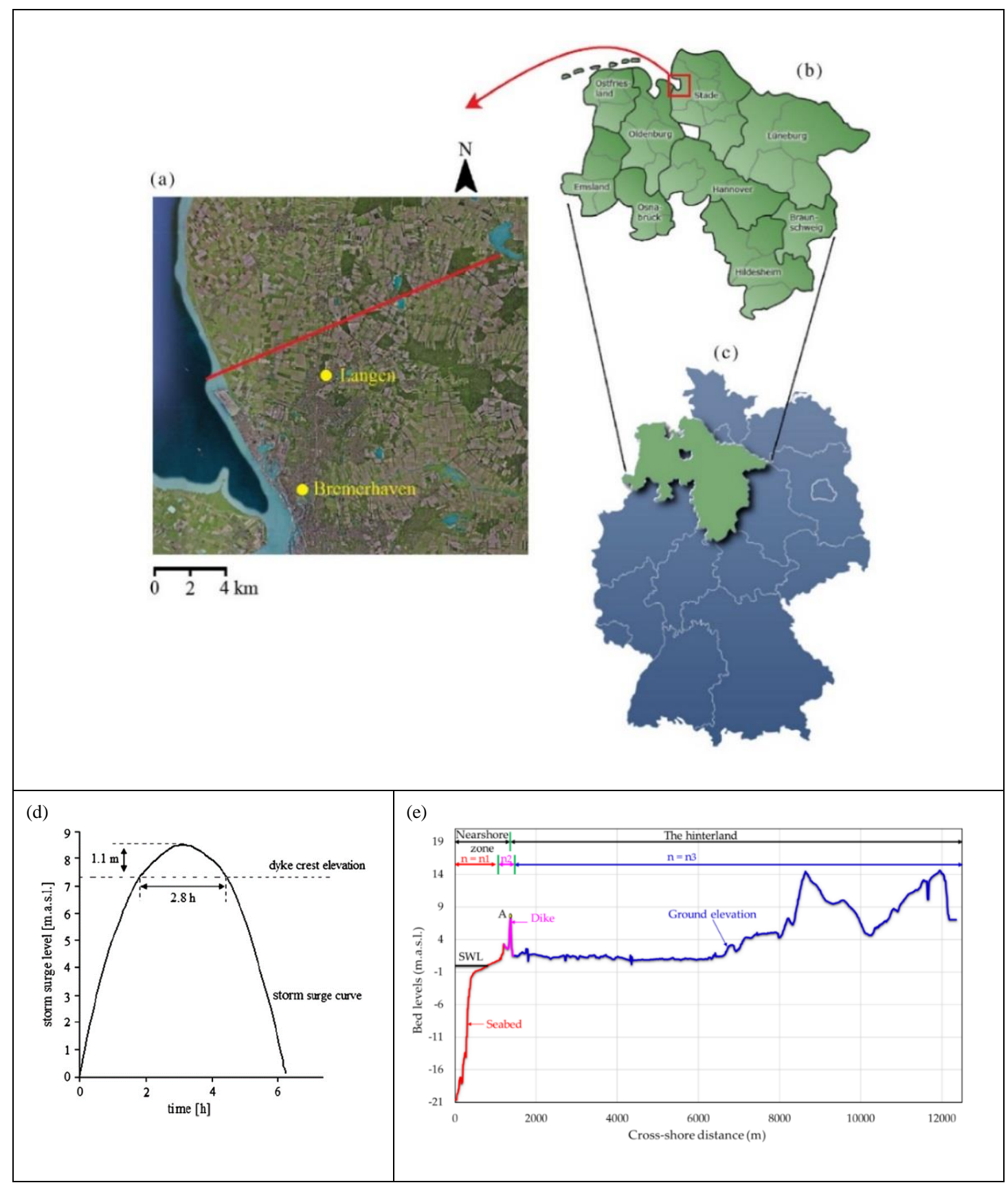

Fig. 8: Location of the study area: (a) selected cross section near Bremerhaven (red line), (b) state of Niedersachsen (Lower Saxony), (c) Germany, (d) applied time history of sea level during a storm surge event for the study site near Bremerhaven: the dashed line represents the elevation of the dyke crest, and (e) bathymetry and ground elevations above the sea water level (m.a.s.l) for the considered cross-shore profile, after Yang et al. (2013).

The extremely high Manning value at the dyke zone $\left(n_{2}=2.592 \mathrm{~m}^{-\frac{1}{3}} . \mathrm{s}\right)$, which was used to prevent dyke overwash, limits indeed the flow velocity over the dyke to be always (i.e. in both Morpho-on and Morpho-off scenarios) under the threshold value for the onset of sediment motion. As a result, no morphological evolution takes place with Morpho-on scenario as this is the case for the Morpho-off 
scenario. When lower friction value $\left(n_{2}=0.00864 \mathrm{~m}^{-\frac{1}{3}} . \mathrm{s}\right)$ is used over the dyke zone with the Morphoon scenario, the dyke is totally overwashed and wider flood extent is obtained (see Elsayed and Oumeraci (2018) for further details). Thus, the inland discharge calculated at the crest of the dyke (Point A in Fig 8.e) is identical for both Morpho-on and Morpho-off scenarios, when $n_{2}$ is set by the former higher value. Therefore, the same inland water volume $(=2196 \mathrm{~m} 3)$ propagates in the hinterland in both scenarios due to this overtopping event. Thus, 54.9 tonnes of salt are supplied to the hinterland and then vertically to the aquifers. Fig (9.a) compares the evolution of the bed and water levels for the simulation scenarios Morpho-on and Morpho-off. It shows that the flood extents for both scenarios are identically increasing with the time marching until water flow is blocked after 10 hours at a cross-shore distance of $6400 \mathrm{~m}$ because of the local increase of the ground elevation at this point. Therefore, the flood extends $5000 \mathrm{~m}$ behind the dyke for both simulation scenarios. Water depths along the $5000 \mathrm{~m}$ are spatially varying because of the spatial variation of the ground surface. Fig (9.b) clearly shows these variations through comparing the initial (at $\mathrm{t}=0 \mathrm{~h}$ ) and the final (at $\mathrm{t}=10 \mathrm{~h}$ ) bed and water levels for both simulation scenarios.

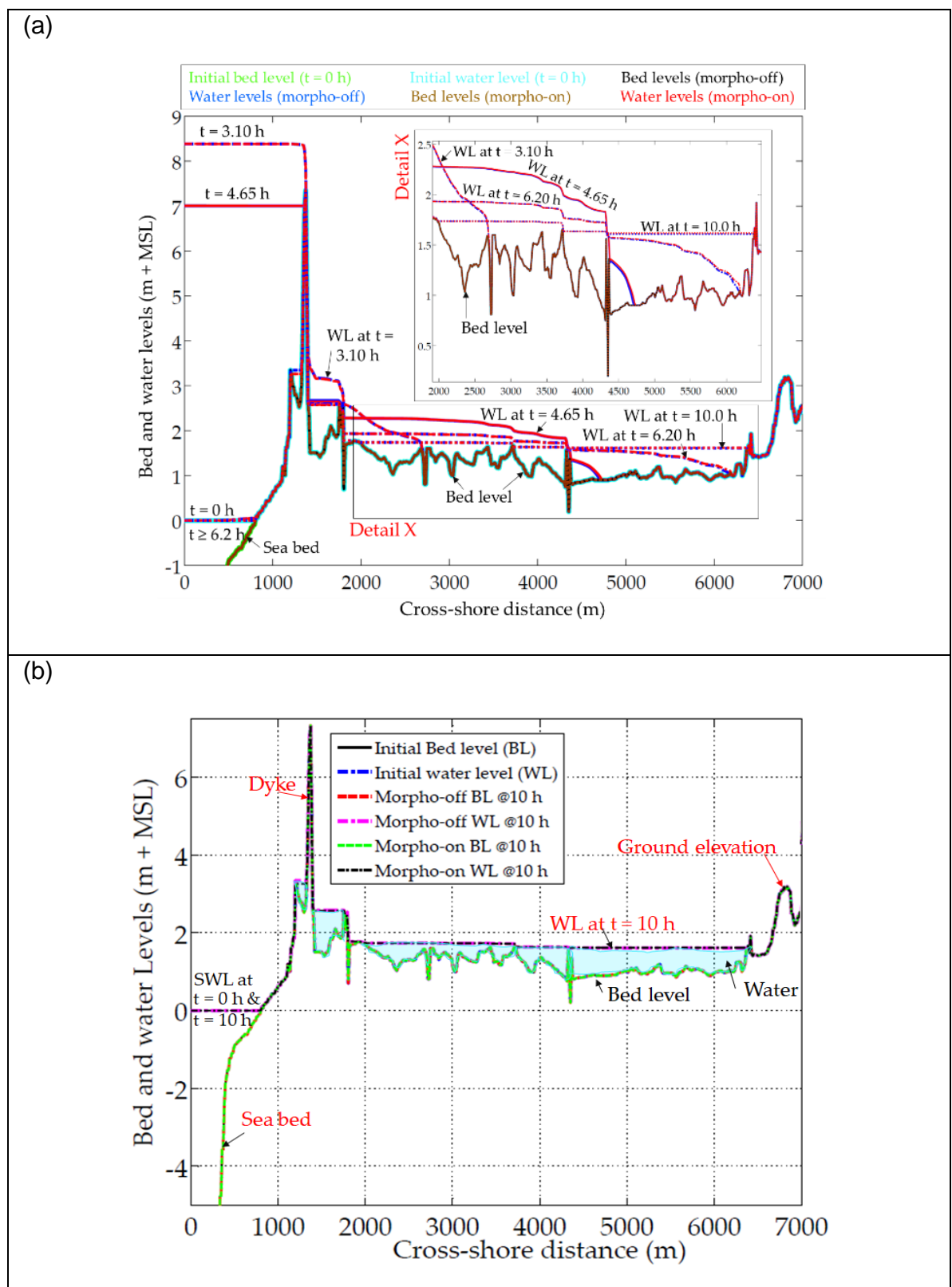

Fig. 9: Coastal flood propagation: (a) evolution of the bed level (BL) and water levels (WL) and (b) Pre- and post-storm sea, inundation and bed levels at Bremerhaven. 
The flood extent and water depth from Fig 9 are used as a surface boundary to simulate the vertical saltwater intrusion using the SEAWAT Model. Elsayed (2017) reported that the overtopped seawater takes 4 days to infiltrate behind the dyke to the aquifer and to induce a disorder of the salt mass budget of the Bremerhaven aquifer due to this coastal flood. The salt concentrations in the aquifers are shown in Fig (10) after 1 day, 3 months, 1 year and 20 years. Before the flood event, only lateral saltwater intrusion induced by the hydraulic interconnectivity between sea and groundwater prevails. After seawater overtopping, the salt water infiltrates into the aquifer along the 5-km flood extent. The contaminant (salt) spreads vertically during the inundation interval as shown in Fig (10) because the infiltrating salt water is heavier in weight than the prevailing freshwater in the aquifer. Even after 3 months and one year, the salt diffusion is still in the vertical direction. Therefore, saltwater moves vertically beneath the flood extent until it mixes with the fresh water over the entire aquifer depth. Such a vertical salt infiltration deviates toward the sea under the effect of seaward directed freshwater flow. In fact, freshwater moving seaward triggers the dilation process in the aquifer as shown in the panels of 1year and 20 years in Fig (10). This dilation process results in a very slow process of natural remediation of the aquifer until the aquifer is remediated totally.
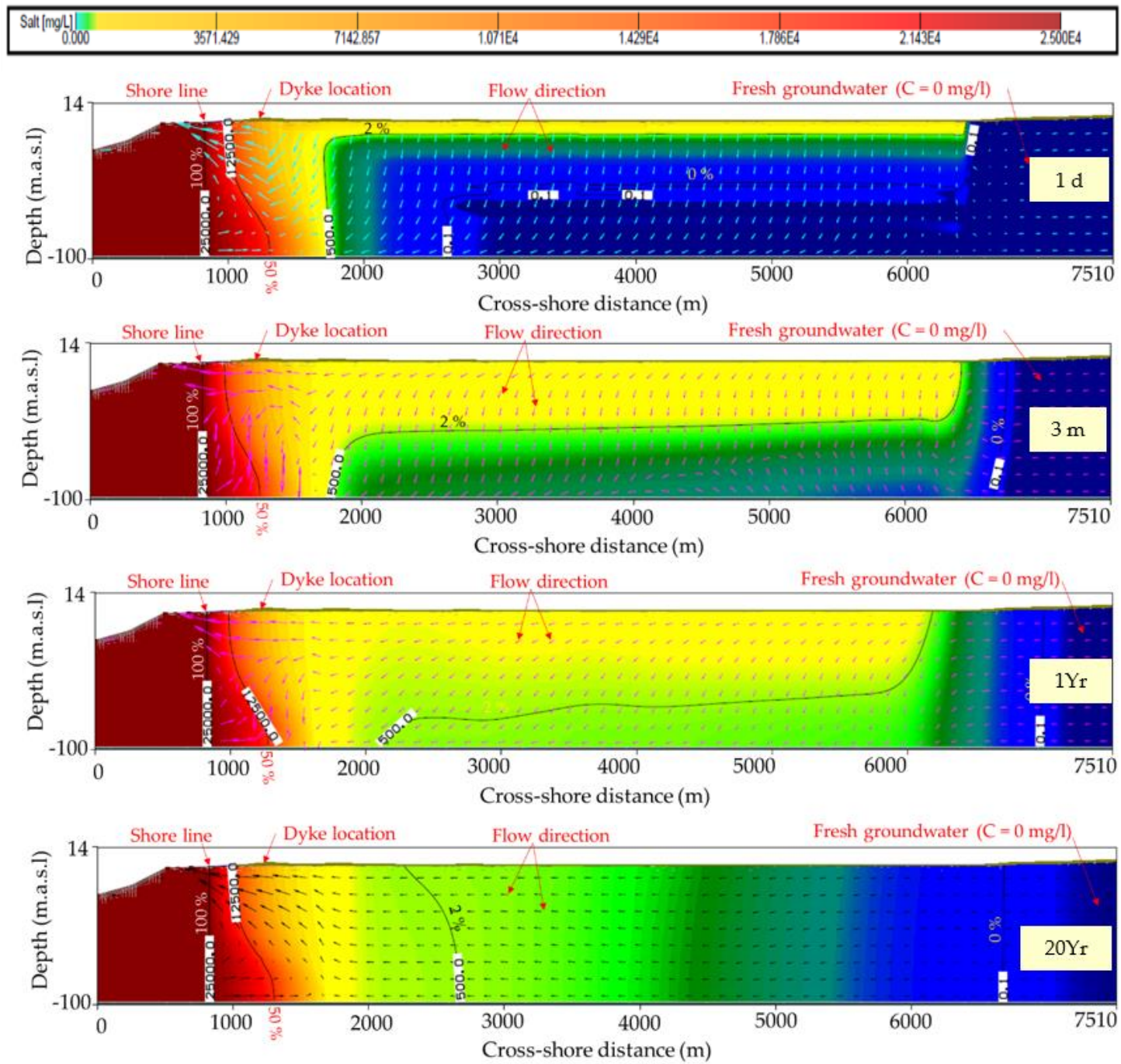

Fig. 10: Evolution of salt distribution in Bremerhaven aquifer after 1 day, after 3 months, after 1 year and after 20 years. Arrows represent flow directions. Intruding salt water from the land surface moves almost vertically until it contaminates the aquifer over its entire depth then it moves horizontally seaward. Salt-freshwater interface is represented by the $50 \%$ iso-concentration contour, and the iso-concentration contour of $500 \mathrm{mg} / \mathrm{l}$ $(2 \%)$ represents the max. salt concentration for drinkable water according to the World Health Organization (WHO).

In order to determine the time of full aquifers remediation of a zero salt concentration and safe use of groundwater as the case before the flood-induced intrusion, Elsayed (2017) used the three curves of 
the salt budget in the aquifers in Fig (11), namely: the accumulative (total) source in mass curve, the accumulative (total) sink out mass curve, and the curve of total mass remaining in the aquifer. The latter curve represents indeed the mismatch between the two former curves, and, therefore, its values can be read separately from the vertical axis on the right. The increase of the source in mass during the percolation interval of 4 days (starting from $t=1,825$ at the end of the warming up time of the model to $\mathrm{t}=1,829)$ is totally stored in the aquifer, as represented by the curve of the total salt mass remaining in the aquifer. This stored mass sinks out the aquifer gradually until the aquifer is totally remediated after 44.3 years. The latter means that freshwater zones in the aquifer, which are affected by the vertical leakage of salt water, will return to its initial state $(0 \mathrm{mg} / \mathrm{L}$ of salt concentration $)$ after this very long time (more than four decades). This recovery is due to the natural remediation of the aquifer owing to the seaward directed flow in addition to the recharged part of rain precipitation on the ground surface. In fact, seaward directed freshwater flow dilutes the infiltrating salt water and moves it gradually seaward until the aquifer is totally remediated. Indeed, the latter processes are extremely slow, and hence very long intervals are needed for total aquifers recovery. This indeed highlights how marine floods might hinder sustainable development of coastal areas prone to floods due to long-term recovery and the increase in treatment costs for water supply and agricultural purposes. When considering the fact that more than $60 \%$ of the world's population lives within $100 \mathrm{~km}$ of coastlines, which gives groundwater a special weightiness as freshwater sources, especially with the really limited surface water availability in coastal zones, finding suitable mitigation measures becomes a crucial and priority research issue. This study tentatively suggested using a subsurface drainage network for this purpose. The rationale behind this selection are discussed in the following section.



Fig. 11: Accumulative salt masses along the fifty years of simulation: Accumulative salt entering the aquifer as a source in, accumulative salt leaving the aquifer as sink out and accumulative salt mass remaining in the aquifer. Detail (b) shows the increase of the source in starting from $t=1,825$ days ( 5 years of warming up) to $t$ $=1,829$ days ( 5 years +4 days) because of the vertical SWI, which results in an increase of the total salt mass in the aquifer by 54.9 tons during the inundation interval ( 4 days). The aquifer is remediated naturally after 44.3 years.

\section{SUBSURFACE DRAINAGE EFFECT ON THE RESILIENCE OF COASTAL AQUIFERS AGAINST MARINE FLOODS}

Most studies associated with vertical saltwater intrusion (e.g. Yang et al., 2013) are limited to the determination of the time interval for the natural remediation process after such events; no suitable structural mitigation measures are proposed to control this type of intrusion and to shorten the commonly long remediation intervals. In fact, besides being a major limitation for the usability of contaminated groundwater for drinking and other subsistence purposes, crops in hinterlands may suffer stress, thereby not grow properly, or may die due to salt intolerance, thus leading to a decrease in the agricultural yield. 
Given their vulnerability, sustainable management of coastal fresh groundwater reserves is of paramount importance.

Management of coastal aquifers involves decisions regarding the amount of water to be extracted and/or injected into the aquifer, taking into account the interplay between the conditions of the aquifer and economic, social factors and, in some cases, environmental impacts. Fig 12 presents the common strategies for controlling lateral SWI into coastal aquifer systems, which is either in the form of upconing induced by excessive pumping and/or in the form of landward shifting of the salt-freshwater interface due to SLR or a long-term decline of the groundwater table (GWT).

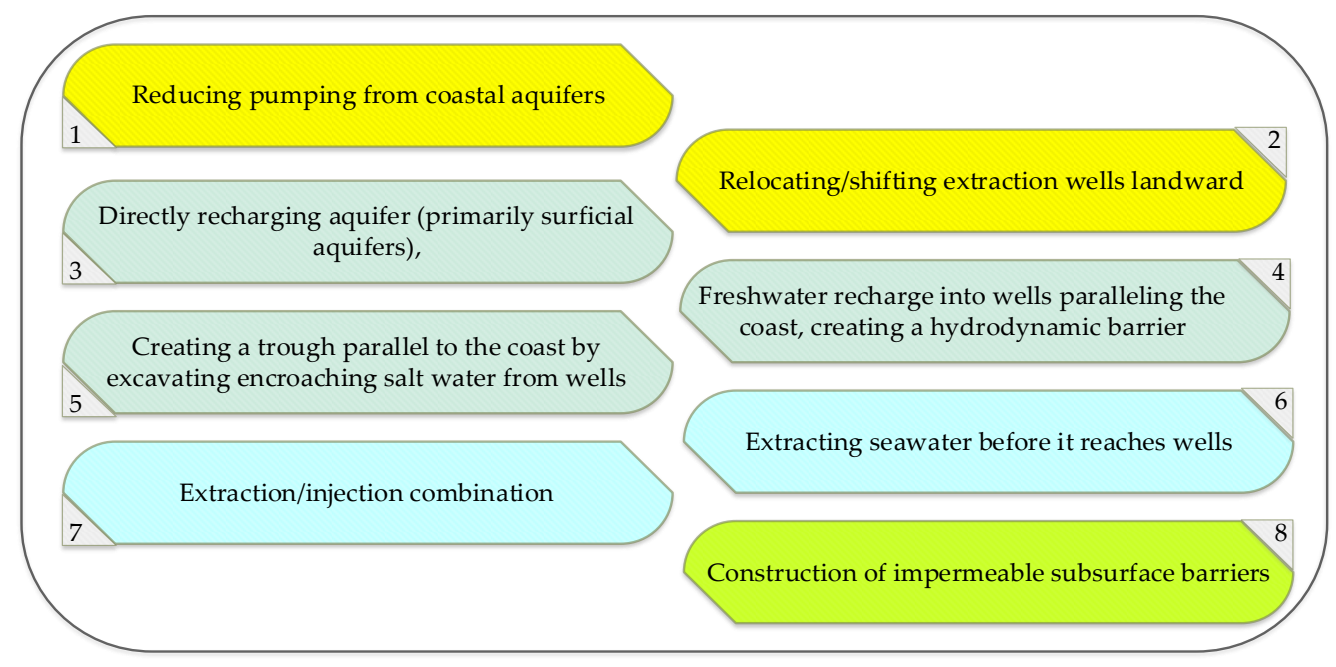

Fig. 12: Common strategies to manage saltwater intrusion into coastal aquifers.

Each of these strategies can be applied to specific locations and conditions, and the method used also depends on the specific problem to be solved. Moreover, simulation tools are often used to evaluate the effectiveness of possible decisions. Nevertheless, none of the previous traditional techniques for managing lateral SWI is suitable for managing vertical SWI induced by coastal inundation. For that reason, Elsayed and Oumeraci (2018a, 2017a) suggested using subsurface drainage system (Fig 13), especially in flood-prone agriculture areas. The drainage, in general, would absorb the contaminated water before reaching the fresh groundwater. However, surface drainage is inappropriate, since it could enlarge the contamination extent and surface drains would act as preferential pathways/open channels for landwards movement of salt water. For this reason, Elsayed (2017) suggested and numerically tested the feasibility of using subsurface drainage system as shown in Fig (13).

The subsurface drains help in lowering the unwanted increase of the GWT in order to enhance growing of crops as shown in Fig (13.a), thus increasing the agricultural yield. Moreover, the simulated subsurface drainage system collected part of the infiltrating salt water, especially during intervals of higher drain conductance, which are often taking place during higher infiltration rates from the land surface. Nevertheless, the rest is escaping downward among the drains, as schematically shown in Fig (13). By comparing both panels of Fig (14) for saltwater distribution in the aquifer near Bremerhaven for both undrained and drained situations at the same time $(t=1$ year after the flood event), it is easy to notice that drainage has proved its efficiency in confining the high salt concentration near to the ground surface. In fact, drainage was capable of controlling the unwanted deeper infiltration of the high salt concentrations in the aquifer. Elsayed (2017) reported that highly concentrated salt water is collected from the shallow zones within the three years after flooding. Moreover, he reported that shorter remediation intervals ( $<3$ years) might be achieved in case of using closer drains, as the wider drains spacing allows more escaping of the saltwater to the deeper freshwater in the aquifer. However, the efficient role of the drainage in shortening the remediation time of the vertical intrusion is often at the expense of more lateral intrusion (as shown in Fig (14) by comparing the 50\% iso-concentration contour in panel (a) for undrained and in panel (b) for drained conditions) because of the drainage-induced lowering of the GWT during intervals of higher drains conductance. 


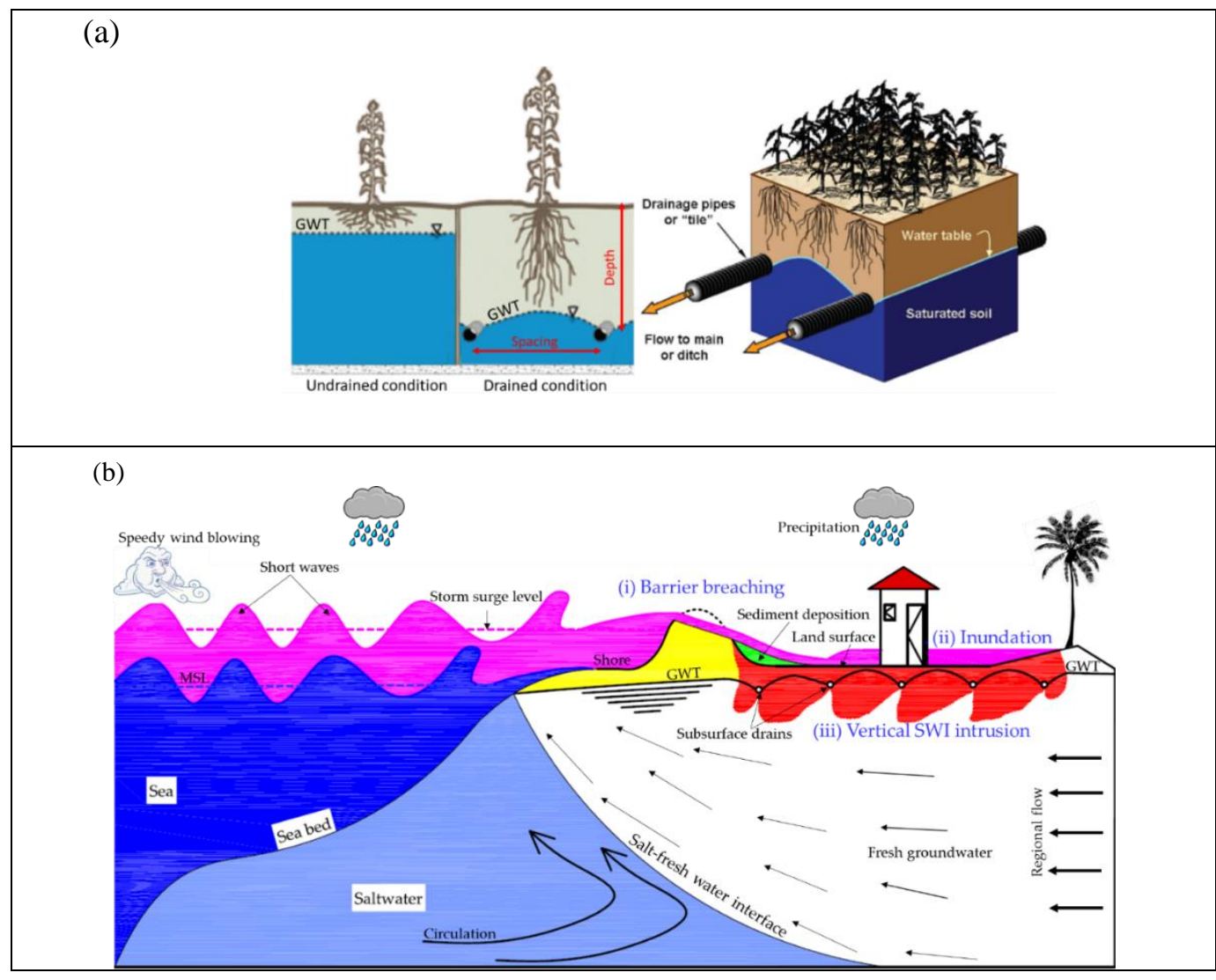

Fig. 13: Subsurface drainage network as a suggestion to mitigate the vertical saltwater intrusion and to shorten long remediation: (a) the role of subsurface drains in lowering the GWT is based on the spacing and depths of the inceptor drains, and (b) Schematic illustration of the flow of salt water through soil with respect to salt leaching and subsurface drainage during and after a storm-induced coastal flood.

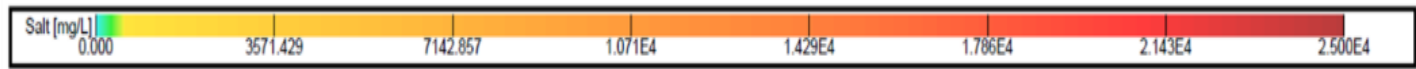


Fig. 14: Salt distribution in the aquifer near Bremerhaven after one year of the flood event (a) with no drainage applied and (b) with subsurface drains. Salt-freshwater interface, represented by the $50 \%$ iso-concentration contour, and the iso-concentration contour of $500 \mathrm{mg} / \mathrm{L}(2 \%)$ are shown on each panel. The interface shifts landward in panel (b) due to the drainage induced lowering of the groundwater table. 
The effect of the drainage on lateral saltwater intrusion might be explained using Fig (15), which compares the mass of salt remaining in Bremerhaven aquifer under both drained and undrained conditions.



Fig. 15: Comparison between salt masses remaining in the aquifer after and before the inundation with and without subsurface drains. The values of drains conductance (Cd) vary from time to another based on the surcharge rate on the ground surface. In the case of drainage, more salt intrudes laterally to the aquifer, especially during higher conductance intervals.

The difference between the two curves in Fig (15) represents the increase of salt mass in the aquifers owing to the lateral intrusion induced by the decline of the GWT because of the subsurface drainage. The assumed values for drains' conductance (Cd) are also shown in Fig (15) while the rationale behind these values are discussed in Elsayed and Oumeraci (2018, 2017a). The mass remaining in the aquifer during the first three years is the same with and without drainage because the conductance of the drains is set at zero (i.e. no drainage). During the following two years, which are also before applying the flood effect, the salt mass remaining in the aquifer increases with drainage as compared to the case without drainage. After these five years, which are considered as warming up phase of the model before applying the flood effect, the flood event is applied for 4 days for both drained and undrained situations, leading to sudden increase of the salt mass in the aquifers by 54.9 tonnes (the same amount of salt that overtopped the dyke). During the first year after applying the flood effect, the conductance value is assumed the highest $\left(\mathrm{Cd}=2 \mathrm{~m} 3 / \mathrm{d}^{*} \mathrm{~m}\right)$, but the mass of salt in the aquifer is increasing dramatically with drainage than without drainage. The latter is because the drainage reduces the GWT, leading to a lateral shift in the saltfreshwater interface landward, as shown in Fig (14) by comparing panels a and b. This increase extends to the second year after flooding until it reaches its peak with the reduction of the conductance value from 1 to $0.06 \mathrm{~m} 3 / \mathrm{d}^{*} \mathrm{~m}$. With the latter reduction, the mass in the aquifer decreases gradually. Nevertheless, the remaining salt mass in the aquifer in the case of using subsurface drainage keep on higher than without drainage even after the 45 years after the flood event because of the lowering of the GWT induced by the drainage.

\section{SUMMARY, LESSONS LEARNT AND IMPLICATIONS FOR PRACTICAL APPLICATIONS}

A new overall modelling approach is developed, using an improved XBeach model and the SEAWAT model, to integrally and successively simulate breaching of coastal barriers, induced inundation and subsequent saltwater intrusion. This modelling approach is used to show that coastal floods induced by a coastal barrier breaching under extreme storm surges represent a significant hazard 
to society, socioeconomic systems and ecosystems. Moreover, such a modelling approach provides an improved understanding of hydro-geo-morphodynamic processes associated with breaching of coastal barriers. Breaching is not necessarily induced by wave overtopping or overflow through local depression on the barrier crest. In addition, it might be initiated from the seaward side of the barrier due to wave impact, run up and run down. As a result, initiating scour from the seaward side might be followed by offshore sediment transport accompanied with seaward avalanching and more lowering of the barrier crest. Thus, with successive crest lowering due to seaward erosion, waves may overtop and then overflow the lowered crest, causing landward erosion and further crest lowering until breach initiation. Furthermore, this modelling approach highlights the importance of considering the mutual interactions among the processes associated with breaching, induced inundation and associated vertical intrusion in order to achieve reliable outcomes.

The problem of overestimation of erosion rates and breaching dimensions by XBeach is tentatively solved by introduced two novel physical processes and implementing them in the current XBeach model. The first improvement demonstrated that net onshore sediment transport depends on the skewness and asymmetry of nonlinear waves. Ignoring or not properly implementing the waveform effect on sediment transport might result in a substantial overestimation of coastal erosion. To overcome this overestimation, this study related the wave nonlinearity effect to the beach slope steepness by relating the net onshore sediment transport to beach slope steepness, so that a better representation of the wave nonlinearity effect on sediment transport and coastal erosion is provided. The second model improvement is related to the soil stabilization effect on coastal sediment transport. The approach proposed in this study is able to explain why erosion rates might differ from one case study to another or from site to another based on the soil-stabilization state. Highly stabilized soils are expected to experience less erosion whilst loose soils are expected to undergo more erosion. Implementation of these two improvements in the current XBeach model contributed to a better prediction of erosion rates and breaching dimensions so that more reliable overtopping rates over earthen barriers and through breaching-induced inlets can be achieved. Accordingly, flood propagation in the hinterland can be better determined.

Determining the inland discharge during a storm surge event over a barrier or through a breach represents one of the important challenges in the coastal engineering field. Overtopping guidelines (e.g. EurOtop) facilitate the assessment of inland discharges induced by overtopping. Nevertheless, these empirical models cannot calculate inland discharges through breaches because of their inherently static nature and hence cannot deal with a dynamic situation such as overwash and breaching of coastal barriers. For the latter purpose, numerical models are often used. This study introduced an approach to calculate inland discharges through breach induced inlet(s) using XBeach. Moreover, it successively extended the scope of XBeach to model not only the breaching but also the subsequent inundation in a single model. The comparison between approaches using breaching model and an inundation model separately and those using a single model for both breaching and induced inundation showed that the former might provide an inaccurate estimation of inundation extents, water depths and inland flow kinematics. Such incorrect estimation arises from the omission of the velocity transfer (momentum conservation) between the breaching and the inundation simulations while considering only the flow (mass) transfer in the form of the inland discharge (inland hydrograph). Moreover, separate modelling cannot account for the dynamic nature of the breaching process. As a result, XBeach is used for combined modelling of barrier breaching and induced inundation, so that mutual interactions between both processes are considered, leading to more reliable flood extent and kinematics. Such combined modelling considers the conservation of both mass and momentum among both processes and hence overcome the drawbacks of decoupled modelling approaches which often provide inaccurate kinematics and flood depths.

This study was capable to highlight the vulnerability of coastal aquifers as a valuable freshwater resource to coastal floods, especially when considering the noticeable demographic movement to coastal cities and the still increasing investments in coastal zones. By applying the XBeach-SEAWAT modelling system to a case study near Bremerhaven, this research showed that a short overtopping event for only $2.8 \mathrm{~h}$ may inundate five kilometres behind the overtopped barrier and may increase the aquifers salinity for more than four decades. This indeed means that such a short flood event may increase the treatment costs over this remediation period and may hinder the agricultural productivity and the sustainable development in coastal areas prone to marine floods.

In order to shorten long remediation intervals after a storm-driven saltwater intrusion event, this study proposed and analysed the performance of a subsurface drainage system which may facilitate the vertically intruding salt water to be absorbed before contaminating the deeper aquifers. This mitigation measure significantly shortens the natural remediation interval and limits the vertical extent of the contamination. Moreover, the installation of such subsurface drainage systems might improve the 
agricultural yield as they contribute to lower the groundwater table. Nevertheless, lowering the groundwater table and shortening the remediation interval are often accompanied by an increased lateral intrusion due to the defection in the hydrostatic equilibrium between the mean sea level and the groundwater table.

Based on the outcomes of this study, the following aspects are recommended for the practical applications:

- The improved XBeach is recommended as a prediction tool to assess vulnerability of coastal defences to surges and to predict inland flow rather than empirical models (e.g. EurOtop).

- Coastal inundation might cause long-term contamination of coastal aquifers. Therefore, it is recommended to include the costs of such contamination to future flood risk assessments. Indeed, such an intangible damage might hinder the development of coastal areas of rarely available water resources.

- Continuous maintenance of the coastal defence systems (e.g. protective dunes and barrier islands) is very crucial to mitigate consequences of possible future flood risk and to protect valuable water resource (e.g. groundwater) from contamination.

- Soil investigations should be considered as an important part of future erosion breaching studies.

- Having highly compacted/consolidated coastal defences that can cope with extreme overtopping without breaching is a crucial issue, especially in highly vulnerable coastal zones.

- For the residual inland discharge due to overtopping, it is recommended to install a suitable subsurface drainage system.

- Lowering the groundwater table in non-coastal areas might be effective in increasing the agricultural yield. However, such lowering in coastal areas might also provide better yields but at the expenses of more lateral SWI because of the hydraulic interconnectivity between the seawater and the groundwater.

- In general, a decline of the groundwater table in coastal areas owing to precipitation decrease, excessive pumping, or subsurface drainage might induce further lateral saltwater intrusion.

- Open channels (e.g. surface drains or channels) should be avoided in coastal vulnerable zones as they might facilitate the enlargement of the contamination extent through acting as preferential pathways for landwards movement of salt water and hence wider extent of VSWI.

- Open wells should be avoided in coastal vulnerable zones as they represent a direct contamination pathway to groundwater.

Because of the long-term effect of VSWI on groundwater resources, further research on consequences of coastal erosion and breaching on such resources should be prioritized and supported by funding agencies, so that more developed modelling approaches might be achieved. Many research gaps still need to be covered, among them: (i) there a need to investigate erosion of composite and nonhomogeneous dykes, (ii) also to consider soil-resistance to erosion over barriers depth and spatially alongshore, (iii) finding a fully coupled model that can simulate, in a single model, the breach, inundation and vertical SWI rather than the weak coupling between XBeach and SEAWAT, and (iv) to investigate more appropriate measures to mitigate the VSWI.

\section{ACKNOWLEDGEMENT}

The author would like to express his sincere gratitude to his doctoral adviser Professor Hocine Oumeraci for the constant guidance and support. I also gratefully thank the Lower Saxony Water Management, Coastal Protection and Nature Conservation Agency (NLWKN) as contracting authority for making the GWK model tests data for Wangerooge for this research project available. The data for the case study near Bremerhaven is gratefully provided by Prof. Dr Thomas Graf and Dr Jie Yang. I also appreciate the help of Dr. Robert McCall from Deltares (the Netherlands), who made many data available for XBeach validation. The presented study was conducted within the author's doctoral studies at the Leichtweiß-Institute from June 2014 to August 2017. Financial support of the German Academic Exchange Service (DAAD) and the German Federal Ministry for Economic Cooperation and Development (BMZ) in the frame of the Exceed-Swindon Project at Technische Universität Braunschweig for the author's doctoral studies is gratefully acknowledged.

\section{REFERENCES}

Bisschop, F., Miedema, S.A., Visser, P.J., Keetels, G.H., van Rhee, C., 2016. Experiments on the Pickup Flux of Sand at High Flow Velocities. Journal of Hydraulic Engineering 142, 04016013. https://doi.org/10.1061/(ASCE)HY.1943-7900.0001142 
Bisschop, F., Visser, P., Van Rhee, C., Verhagen, H.J., 2010. Erosion due to high flow velocities: a description of relevant processes, in: Proceedings of 32nd International Conference on Coastal Engineering ICCE. p. 10. http://dx.doi.org/10.9753/icce.v32.sediment.24

D'Eliso, C., 2007. Breaching of sea dikes initiated by wave overtopping;A tiered and modular modelling approach. PhD dissertation, TU Braunschweig and University of Florence, Braunschweig, Germany.

De Vet, P., 2014. Modelling sediment transport and morphology during overwash and breaching events. M.Sc. dissertation, Delft University of Technology, Delft, the Netherlands, Delft - The Netherlands.

Elsayed, S.M., 2017. Breaching of Coastal Barriers under Extreme Storm Surges and Implications for Groundwater Contamination. PhD dissertation, Leichtweiß Institute for Hydraulic Engineering and Water Resources, TU Braunschweig, Braunschweig, Germany. Available at: https://dx.doi.org/10.24355/dbbs.084-201710161043

Elsayed, S.M., Oumeraci, H., 2018. Modelling and Mitigation of Storm-Induced Saltwater Intrusion: Improvement of the Resilience of Coastal Aquifers Against Marine Floods by Subsurface Drainage. $\begin{array}{lllll}\text { Environmental } \quad \text { Modelling } & \text { and }\end{array}$ https://doi.org/10.1016/j.envsoft.2017.11.030

Elsayed, S.M., Oumeraci, H., 2017a. Breaching of Coastal Barriers under Extreme Storm Surges and Implications for Groundwater Contamination: Implications of coastal floods for groundwater contamination. Internal Report no 1075, Leichtweiß-Institut for Hydraulic Engineering and Water Resources, TU Braunschweig, Braunschweig, Germany. available at: https://www.researchgate.net/publication/316459814_Implications_of_coastal_floods_for_ground water_contamination.

Elsayed, S.M., Oumeraci, H., 2017b. Modelling and management of storm-driven saltwater intrusion in freshwater aquifers: The case of near Bremerhaven, Germany, in: Silva, R., Chavez, V. (Eds.), Integrating Ecosystems in Coastal Engineering Practice (INECEP). Cuvillier Verlag, Puerto Morelos, Mexico, pp. 150-168.

Elsayed, S.M., Oumeraci, H., 2017c. Effect of beach slope and grain-stabilization on coastal sediment transport: An attempt to overcome the erosion overestimation by XBeach. Coastal Engineering 121, 179-196. https://doi.org/10.1016/j.coastaleng.2016.12.009

Elsayed, S.M., Oumeraci, H., 2016a. Combined Modelling of Coastal Barrier Breaching and Induced Flood Propagation Using XBeach. Hydrology 3, 34. https://doi.org/10.3390/hydrology3040032

Elsayed, S.M., Oumeraci, H., 2016b. Breaching of Coastal Barriers under Extreme Storm Surges and Implications for Groundwater Contamination: Application of XBeach in Coastal Flood Propagation. Internal Report no 1074, Leichtweiß-Institut for Hydraulic Engineering and Water Resources, TU Braunschweig. Braunschweig, Germany. Available at: https://www.researchgate.net/publication/315739116_Application_of_XBeach_in_Coastal_Flood_ Propagation.

Elsayed, S.M., Oumeraci, H., 2015a. Breaching of Coastal Barriers under Extreme Storm Surges and Implications for Groundwater Contamination: Assessment of the XBeach Model Performance under Storm Surges using GWK-Data. Internal Report no 1072, Leichtweiß-Institute for Hydraulic Engineering and Water Resources, TU Braunschweig. Available at: https://www.researchgate.net/publication/316351876_Breaching_of_Coastal_Barriers_under_Extr eme_Storm_Surges_and_Implications_for_Gr.

Elsayed, S.M., Oumeraci, H., 2015b. Breaching of Coastal Barriers under Extreme Storm Surges and Implications for Groundwater Contamination: Improvement and Extension of the XBeach Model to Account for New Physical Processes. Internal Report no 1073, Leichtweiß-Institut for Hydraulic Engineering and Water Resources, TU Braunschweig, Braunschweig, Germany. Available at: https://www.researchgate.net/publication/315819318_Improvement_and_Extension_of_the_XBea ch_Model_to_Account_f.

Langevin, C., Jr, D.T., Dausman, A., Sukop, M., 2008. SEAWAT Version 4: A computer program for simulation of multi-species solute and heat transport. Virginia.

McCall, R.T., Van Thiel de Vries, J.S.M., Plant, N.G., Van Dongeren, A., Roelvink, J.A., Thompson, D.M., Reniers, A.J.H.M., 2010. Two-dimensional time dependent hurricane overwash and erosion modeling at Santa Rosa Island. Coastal Engineering 57, 668-683.

Muller, H., Rooijen, A. van, Idier, D., Pedreros, R., Rohmer, J., 2016. Assessing Storm Impact on a French Coastal Dune System Using Morphodynamic Modeling. Journal of Coastal Research. https://doi.org/10.2112/JCOASTRES-D-15-00102 
Park, W.K., Moon, Y.H., Chang, S.Y., Jeong, W.M., Chae, J.W., Ryu, K.H., Chang, Y.S., Jin, J.Y., 2018. Nonlinear Transformation of Storm Waves and Impacts on Nearshore Mound in Haeundae Beach, Korea. Journal of Coastal Research 85, 1131-1135. https://doi.org/10.2112/SI85-227.1

Roelvink, D., Reniers, A., van Dongeren, A., van Thiel de Vries, J., McCall, R., Lescinski, J., 2009. Modelling storm impacts on beaches, dunes and barrier islands. Coastal Engineering 56, 1133-1152. https://doi.org/10.1016/j.coastaleng.2009.08.006

Stanczak, G., 2008. Breaching of sea dikes initiated from the seaside by breaking wave impacts. $\mathrm{PhD}$ dissertation,Leichtweiß-Institute for Hydraulic Engineering and Water Resources, Technische Universität Braunschweig, Braunschweig, Germany.

Van der Meer, J.W., Allsop, N.W.H., Bruce, T., De Rouck, J., Kortenhaus, A., Pullen, T., Schüttrumpf, H., Troch, P., Zanuttigh, B., 2016. EurOtop II 2016: Manual on wave overtopping of sea defences and related structures An overtopping manual largely based on European research, but for worldwide application, 2nd ed.

Vousdoukas, M.I., Voukouvalas, E., Mentaschi, L., Dottori, F., Giardino, A., Bouziotas, D., Bianchi, A., Salamon, P., Feyen, L., 2016. Developments in large-scale coastal flood hazard mapping. Natural Hazards and Earth System Sciences 16, 1841-1853. https://doi.org/10.5194/nhess-16-1841-2016

Yang, J., Graf, T., Herold, M., Ptak, T., 2013. Modelling the effects of tides and storm surges on coastal aquifers using a coupled surface-subsurface approach. Journal of Contaminant Hydrology 149, 6175. https://doi.org/10.1016/j.jconhyd.2013.03.002 